\title{
Cold storage Condensation Heat Recovery System with a Novel Phase Change Composite Material
}

Mingzhu Xia ${ }^{\mathrm{a}}$, Yanping Yuan ${ }^{\mathrm{b}, *}$, Xudong Zhao ${ }^{\mathrm{c}, ~}$, Xiaoling Cao ${ }^{\mathrm{b}}$, Zhonghua Tang ${ }^{\mathrm{a}}$ a. School of Civil Engineering and Architecture, Southwest University of Science and Technology, Mianyang, 621010, China

b. School of Mechanical Engineering, Southwest Jiaotong University, Chengdu, 610031, China c. School of Engineering, University of Hull, Cottingham Road, Hull, UK

[Abstract] Cold storage systems release huge amount of condensation heat into the ambient leading to severe environmental pollution and significant energy waste. On the other hand, research into phase change materials appropriate to heat recovery in cold storages has not yet been well reported. The paper presented a dedicated study into a novel phase change composite material appropriate to this kind of application, which has relatively larger latent heat and thermal conductivity, and appropriate phase change temperature (i.e. $80^{\circ} \mathrm{C}$ ). Taking Carnauba Wax (CW) as the Phase Change Material (PCM) and the highly thermal conductive porous expanded graphite (EG) as the additive, a composite was thus developed at the mass ratio of 10:1 that was recognized as the optimal mixing rate. Thermal \& physical properties and interior structure of the composite were then investigated by using the scanning electron microscope (SEM), thermal constants analyzer (Hot Disk), differential scanning calorimeter (DSC), and Fourier transform infrared spectrometer (FT-IR). Furthermore, experiments on the melting \& solidification and the accelerated cooling \& heating cycling were also undertaken. It is found that at the optimal mass ratio, temperatures of the CW/EG composite in the melting and solidification processes were $81.98^{\circ} \mathrm{C}$ and $80.43^{\circ} \mathrm{C}$ respectively, while the corresponding latent heats were $150.9 \mathrm{~J} / \mathrm{g}$ and 142.6J/g. During both processes, the CW could retain its original vermiform structure after being completely adsorbed by the EG. Compared to the CW alone, the melting and solidification timings of the CW/EG composite were reduced by $81.7 \%$ and $55.3 \%$ respectively; while its thermal conductivity became 17.4 times higher. After undertaking around 1000 runs of accelerated cooling \& heating cycling, the endothermic/exothermic phase change temperatures of the CW and CW/EG composite were increased by only $0.42 \% / 0.42 \%$ and $0.23 \% / 0.27 \%$ respectively; while their endothermic/exothermic latent heats were reduced by $4.96 \% / 4.78 \%$ and $2.05 \% / 3.44 \%$. These 
results indicate that both the CW and CW/EG have excellent thermal stability while the CW/EG composite presents a slight better performance. This research, by developing and characterizing a PCM composite appropriate to cold storage condensation heat recovery application, has significant importance to achieving the energy saving and carbon reduction targets in the refrigeration sector, both in China and globally.

[Keywords] Phase change material; Carnauba wax; Expanded graphite; Thermal and physical properties

\section{Introduction}

It is well known that huge amount of condensation heat in cold storage refrigeration systems is being released to the ambient which has caused severe environment pollution and significant energy waste. If this amount of heat could be appropriately recycled to provide space heating and hot water for households, significant energy saving will be achieved and consequently, environmental pollution will be greatly mitigated. To date, research on condensation heat recovery in cold storage systems is still in its infancy, with the major focuses on the economic analysis and system design ${ }^{[1-3]}$. Using the Phase Change Materials (PCMs) to conduct heat recovery in cold storage systems is regarded as an initiative effort.

Owing to larger amount of latent heat and approximately isothermal phase changing process, the PCM based heat recovery system has advantages of smaller size and relatively stable operational process, compared to conventional heat recovery systems using sensible heat of the water ${ }^{[4-5]}$. Researches on the PCMs for condensation heat recovery in conventional air conditioning systems were well established ${ }^{[6-10]}$. To give a few examples, Fang et al ${ }^{[11]}$ developed a SA/EG composite using Stearic Acid (SA) as the PCM and Expanded Graphite (EG) as the additive. Various mass ratios between the SA and EG were investigated, indicating that a ratio of 5 to 1 could stop the separation of the liquid SA from the composite; while the composite of this mass ratio could achieve the highest latent heat and thermal conductivity. Yuan et $\mathrm{al}^{[12-14]}$ studied a couple of organic PCMs including the fatty acids and fatty-acid/EG composite, indicating that the organic PCM composite could achieve the required phase change temperature, increased latent heat and 
thermal conductivity, reduced super-cooling, and stable chemical performance and geometrical shape, and thus is appropriate to condensation heat recovery application in general air conditioning systems.

However, little report was yet found in study of the PCMs specifically for condensation heat recovery in cold storage systems. Owing to the difference in refrigerant state under two cyclic operations, especially in its temperature at the outlet of the compressor $\left(65-85^{\circ} \mathrm{C} \cdot \mathrm{vs} \cdot 90-150^{\circ} \mathrm{C}\right)$, the PCMs applicable to conventional air conditioning systems are not appropriate to cold storage application. In this circumstance, it is important to develop and characterize a few new PCM composites that have right phase change temperature and thermal \& physical properties to enable its appropriate application in cold storage condensation heat recovery.

\section{Cold storage condensation heat recovery principle and PCM composites selection}

Fig. 1 shows the schematic of a cold storage refrigeration system incorporating a PCM heat recovery unit. Its work principle could be demonstrated as such: during the heat recovery operation, the refrigerant leaving off the gas-liquid separator (No 11) is directed into the compressor (No 1) and then to the oil separator (No 2) where it is pressurized and heated, thus becoming high pressure super-critical vapour. By turning the valve K2 on and switching the valve K3 off, the vapour leaving off the oil separator is introduced into the PCM heat recovery unit (No 3) where the heat exchange between the vapour refrigerant and PCM block takes place, leading to recovery of the condensation heat from the vapour refrigerant. The vapour leaving off the PCM heat recovery unit is then delivered to the condenser (No 4) where phase change of the refrigerant takes place, leading to the condensation of the vapour refrigerant. The condensed liquid refrigerant is then forced through the expansion valve (No 9), leading to the significant fall in both the pressure and temperature. Afterwards, the low temperature/pressure liquid is delivered into the evaporator (No 10) installed in the heat storage where heat is extracted from the storage space, thus creating a low temperature environment. As a result, the refrigerant leaving off the evaporator is vaporized and this is then delivered to the gas-liquid separator (No 11) for separation of the liquid refrigerant from the vapour flow, thus completing a refrigerant cycling operation. As the condensation temperature in a cold storage system should be as low as possible (less than $40^{\circ} \mathrm{C}$ ), 
phase change temperature of the selected PCMs should be around $80^{\circ} \mathrm{C}$ to enable effective heat recovery during the refrigerant condensation process.

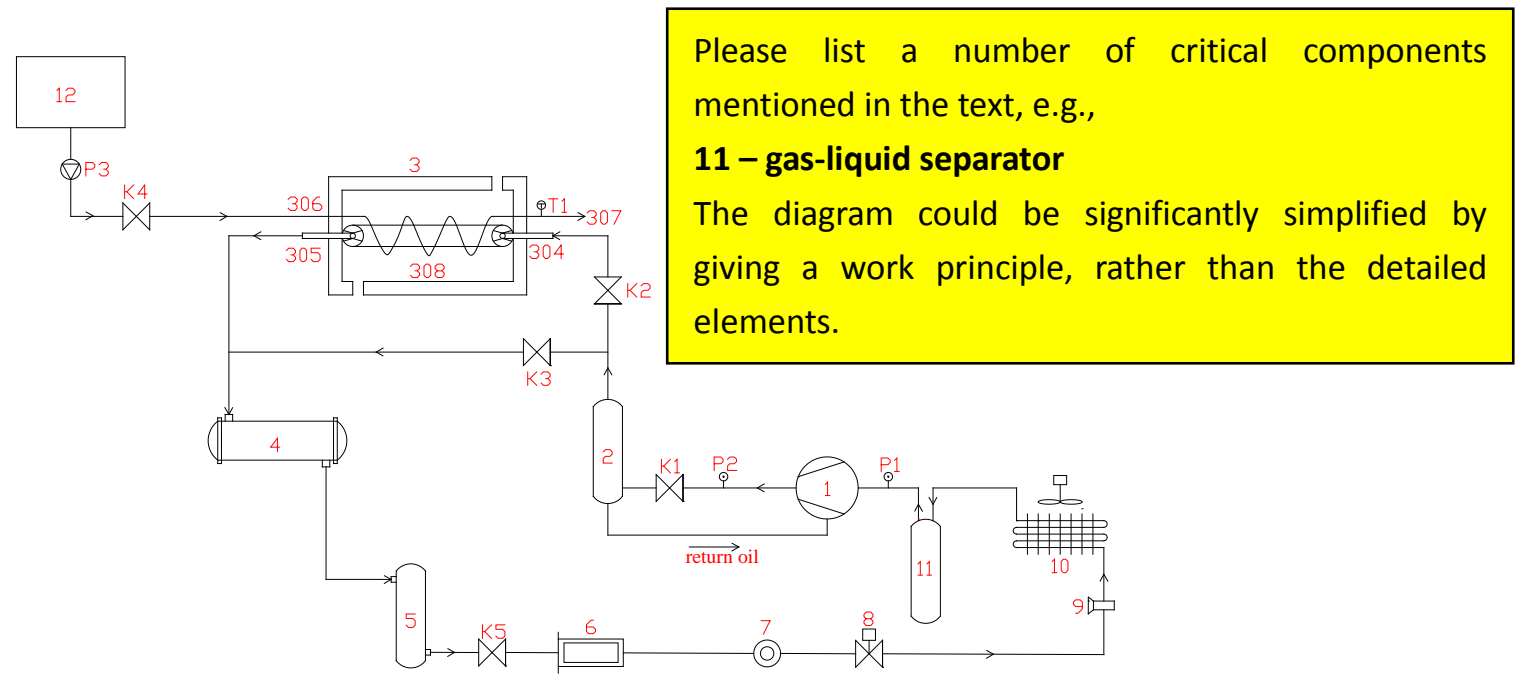

Fig. 1. Schematic of the refrigeration system with PCM heat recovery unit for cold storage application

Selection of the phase change materials should examine their thermal, chemical and physical performance and economic measures ${ }^{[15]}$. In terms of the thermal properties, the selected PCM should have (a) an appropriate phase change temperature; (b) a larger phase changing latent heat, and (c) a larger thermal conductivity. In terms of the chemical performance, the PCM should have (a) no liquidation phenomena during the phase transition process; (b) no super-cooling; (c) steady operational performance during the reversible melting and solidification processes; and (d) the features of non-flammable, non-toxic, non-corrosive, and compatible to the container materials. In terms of the physical performance, the selected PCM should have a relatively smaller volume expansion rate, a larger density and a lower vapour pressure. Furthermore, the selected material should be easy to obtain and economically feasible.

On the basis of these criteria, initial screening into potential PCMs was carried out, suggesting that the Carnauba Wax (CW) may be an appropriate candidate that could approximately meet all the addressed requirements. However, its low thermal conductivity appeared to be a distinct disadvantage that is similar to most currently available PCMs ${ }^{[16]}$. To overcome this disadvantage, many methods have been proposed to enhance the thermal conductivity of the PCMs. The common method ${ }^{[17-27]}$ is to add metals or other thermally conductive carbon powders (such as 
graphite, expanded graphite (EG), etc.) into PCMs. This method was proved to be effective in enhancing the thermal performance of the composite but meanwhile, brought about problems of the heavy mass load and poor PCM uniformity within the composite, owing to the higher density and severe gravitational sedimentation with metal powders ${ }^{[28]}$.

Compared to metal powders, the graphite and expanded graphite (EG) have slightly lower thermal conductivities, i.e., $50 \sim 150 \mathrm{~W} / \mathrm{m} \cdot \mathrm{K}$ and $300 \mathrm{~W} / \mathrm{m} \cdot \mathrm{K}$ respectively. However, the two additives have also low mass density and consequently reduced sedimentation that could mitigate the non-uniformity problem of the PCM within the composite. The additional advantage of the EG lies in its capability of absorbing the liquid PCM owing to its high surface tension and capillary forces, thus leading to a well mixed and highly thermal conductive PCM composite. Table 1 presents the thermal and physical properties of the CW and EG.

Table 1. Thermal \& physical properties of the Carnauba Wax (CW) and Expanded Graphite (EG)

\begin{tabular}{cccccc}
\hline $\begin{array}{c}\text { phase } \\
\text { change } \\
\text { material }\end{array}$ & $\begin{array}{c}\text { Melting } \\
\text { point } \\
{ }^{\circ} \mathrm{C}\end{array}$ & $\begin{array}{c}\text { Phase change } \\
\text { latent heat } \\
\mathrm{J} / \mathrm{g}\end{array}$ & $\begin{array}{c}\text { Thermal } \\
\text { conductivity } \\
\mathrm{W} /(\mathrm{m} \cdot \mathrm{k})\end{array}$ & $\begin{array}{c}\text { Density } \\
\left(25^{\circ} \mathrm{C}\right) \\
\mathrm{g} / \mathrm{cm}^{3}\end{array}$ & $\begin{array}{c}\text { Volume heat } \\
\text { capacity } \\
\mathrm{MJ} /\left(\mathrm{m}^{3} \cdot \mathrm{k}\right)\end{array}$ \\
\hline $\mathrm{CW}$ & $80 \sim 88$ & 168.3 & 0.3403 & $0.996 \sim 0.998$ & 1.455 \\
EG & $3800 \sim 3900$ & - & 300 & 1.1 & - \\
\hline
\end{tabular}

In light of these considerations, the CW was finally selected as the phase change material while the EG was selected as the additive, both of which were mixed at the pre-determined mass ratios, thus forming a new PCM composite appropriate to cold storage condensation heat recovery application. During the preparation process, the EG, which has the carbon content of 99\%, mesh number of 80 , and expansion coefficient of $200 \mathrm{~mL} / \mathrm{g}$, was heated for the duration of 60 seconds in a microwave oven. The CW and EG was then mixed at 12 different mass ratios, as shown in Table 2. The developed CW/EG composite samples were then put into a vacuum drying box for vacuum treatment, which, set to a temperature of $100^{\circ} \mathrm{C}$, was run for the duration of 12 hours. Afterwards, the composite samples were taken away from the box and stirred by a glass rod for a while. These samples were again put back into the box for another 12-hour vacuum treatment. To the end, the samples were exposed to the air for processing natural cooling. 


\section{Characterization of the PCM composites by experiments}

Characterization of the PCM composites was then carried out by using the scanning electron microscope (SEM), differential scanning calorimeter (DSC), Fourier transform infrared spectrometer (FT-IR), and thermal constants analyzer (Hot Disk). This enabled determination of the optimal CW/EG mass ratio in the composite, its micro/macro-structure and thermal \& physical properties that could be used in future PCM system design and analyses. These works are detailed below:

\subsection{Determination of the optimal CW/EG mass ratio}

The latent heat in phase change is a major indicator used for evaluating the performance of heat recovery systems. It is clear that a higher latent heat can lead to an enhanced system performance. In a PCM composite, a higher proportion of CW can create a greater latent heat for the mix, as the EG, being a highly thermal conductive material, cannot contribute to any enhancement in phase changing heat capacity. On the other hand, proportion of the CW in a composite should not break the upper limit, as beyond which the liquid leakage would take place during the melting process. In this case, an optimal mass ratio between the CW and EG should be in existence that needs an appropriate examination.

Table 2 presents 12 sets of CW/EG samples (i.e., M1 - M12) which have the mass ratio in the range 100:1 to 8.3:1. These samples were macroscopically examined to find out whether or not the liquid leakage phenomenon would occur. It was found that when being taken away from the vacuum drying over, certain wetting areas were easily observed in samples M1-4. While after the solidification, lumps of redundant PCMs were found in the samples M1-4 that were adhered to the side/bottom walls of the beaker. These indicated the mass of the CW in the M1-4 samples had exceeded the adsorptive capacity of the EG. In this case, samples M1-4 should be excluded.

Table 2. The CW/EG mass ratio 


\begin{tabular}{ccccccccccccc}
\hline Samples & M1 & M2 & M3 & M4 & M5 & M6 & M7 & M8 & M9 & M10 & M11 & M12 \\
\hline EG(g) & 0.1 & 0.2 & 0.3 & 0.4 & 0.5 & 0.6 & 0.7 & 0.8 & 0.9 & 1 & 1.1 & 1.2 \\
CW(g) & 10 & 10 & 10 & 10 & 10 & 10 & 10 & 10 & 10 & 10 & 10 & 10 \\
CW/EG(g) & 10.1 & 10.2 & 10.3 & 10.4 & 10.5 & 10.6 & 10.7 & 10.8 & 10.9 & 11 & 11.1 & 11.2 \\
EG:CW/EG(\%) & 0.99 & 1.96 & 2.91 & 3.85 & 4.76 & 5.66 & 6.54 & 7.41 & 8.26 & 9.09 & 9.91 & 10.71 \\
\hline
\end{tabular}

Study into remaining samples (i.e., M5-12) continued. 0.3g of M5-M12 samples were weighed and placed into the round filter papers of $2.2 \mathrm{~cm}$ in diameter, with one each. These samples were then put into a drying box of $100^{\circ} \mathrm{C}$. After a certain time duration (i.e., 2 hours), they were taken away and examined in terms of the permeation condition, with the results shown in Table 3.

Table 3. Permeation condition of the CW/EG with filter paper method in different mass ratios

\begin{tabular}{ccccccccc}
\hline Samples & M5 & M6 & M7 & M8 & M9 & M10 & M11 & M12 \\
\hline Weight(g) & 0.30022 & 0.30049 & 0.30010 & 0.30056 & 0.30052 & 0.30080 & 0.30011 & 0.30016 \\
$\begin{array}{c}\text { Permeation } \\
\text { condition }\end{array}$ & large & middle & small & little & minim & Nothing & nothing & nothing \\
\hline
\end{tabular}

It was found that for the samples M5-9, different-sized mimeograph circular markings were appeared on the filter papers, indicating that the samples M5-9 contained over-weighed CW masses that were extracted during the melting process. In this case, samples M5-9 could be excluded.

Unlike the M1-9 samples, the filter papers with samples M10-12 had no any mimeograph markings appeared. This indicated the CW masses within the samples M10-12 were less than the EG's absorptive capacity. Of the last three samples, M10 contained the least amount of the EG and therefore had the highest latent heat. From this point of view, sample M10 should be the best selection, which has the CW/CE mass ratio of 10:1.

\subsection{Micro-structural performance}

The micro-structural performance of the PCM composites was measured by using the scanning electron microscopy (SEM) (FEI, Netherlands, model number S50). Fig. 2 shows the microscopic images of the EG and CW/EG with mass ratio of 10:1, which were taken by the SEM under different microscopic scales including x100, x500, and x1,000. Comparison among these images 
showed that the EG became a loose curled vermiform structure after a high temperature heating treatment, which had the meshed-pores appearance on the surface. In terms of the shape and sizes, the pores were presented in a slit or polygonal geometry, with the dimension ranging from a few microns to tens of microns. Such a porous characteristics of the EG created enhanced surface adsorption capacity and thus, allowed full range of adsorption to the CW while its original vermiform structure remained the same. By means of the capillary and surface tension forces of the EG meshed-pores, the CW liquid leakage could be effectively prevented. Furthermore, no block or strip markings was observed on the EG surface after taking a full CW adsorption, indicating that the CW was fully adsorbed by the pores on the EG surface.

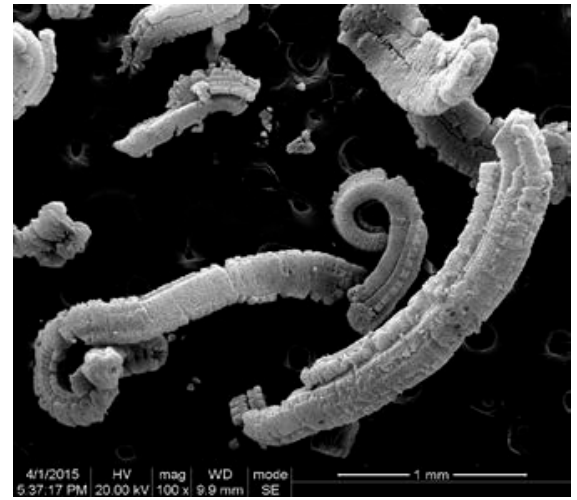

(a) $\times 100$ EG

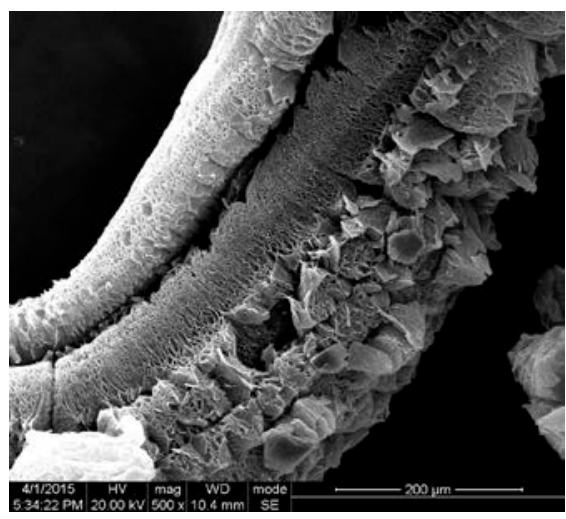

(c) $\times 500$ EG

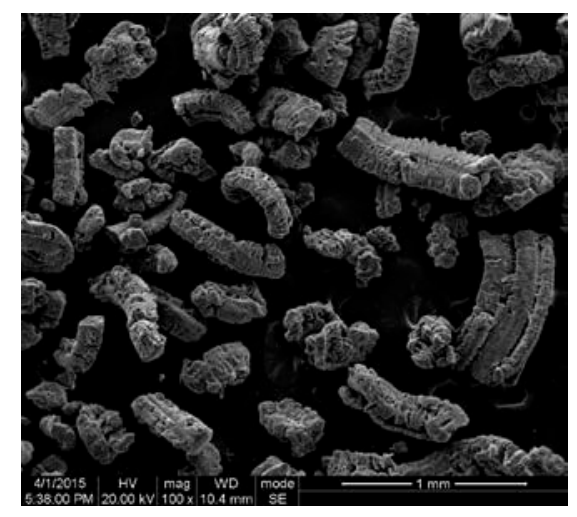

(b) $\times 100$ composite $\mathrm{PCM}$

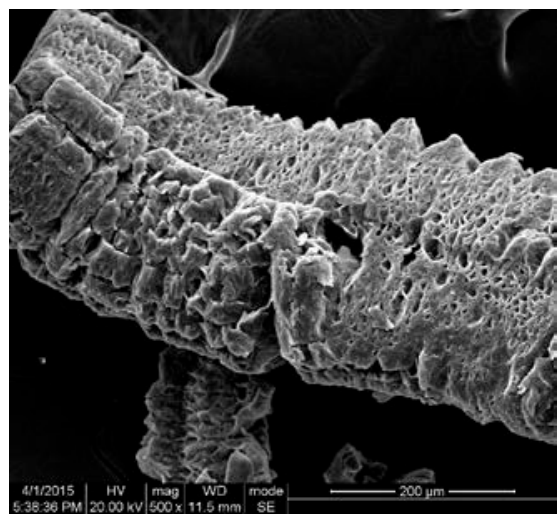

(d) $\times 500$ composite PCM 


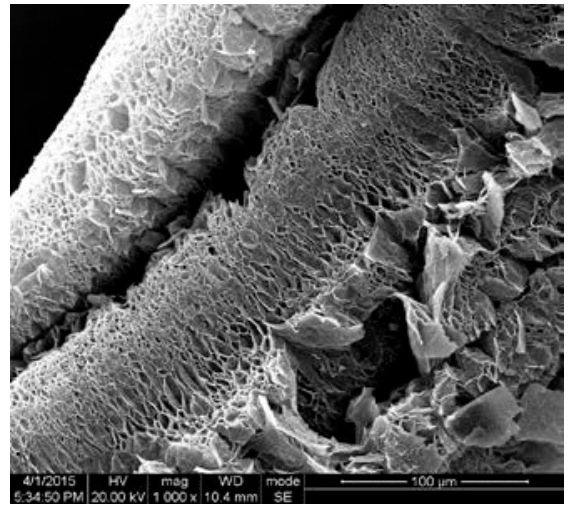

(e) $\times 1,000$ EG

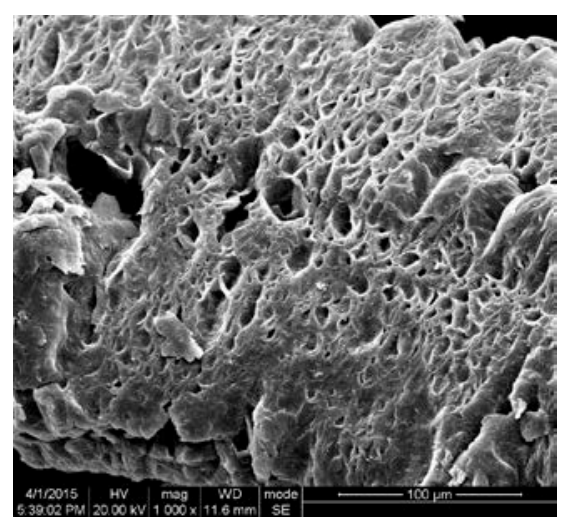

(f) $\times 1,000$ composite PCM

Fig. 2. SEM images under different magnifications

\subsection{Macroscopic performance}

The macroscopic structure of the CW, EG and CW/EG was measured by using the Fourier transform infrared spectrometer (FT-IR, Thermo Fisher company in United States, model number Nicolet 6700), thus giving the infrared spectrums of the CW, EG and CW/EG composite as shown in Fig. 3(a). The broad absorption peak of the CW at $3446 \mathrm{~cm}^{-1}$ represented the stretching vibration of the intermolecular -OH groups; the absorption peak at 2918 and $2849 \mathrm{~cm}^{-1}$ stood for the symmetric stretching vibrations of $-\mathrm{CH}_{3}$ and $-\mathrm{CH}_{2}$ group; while the absorption peak at $1736 \mathrm{~cm}^{-1}$ reflected the stretching vibration of $\mathrm{C}=\mathrm{O}$. The peaks at 1463 and $719 \mathrm{~cm}^{-1}$ were the characteristic absorption figures for the bending vibration of the functional group of the $-\mathrm{OH}$ in $\mathrm{CW}$, while the absorption peak at $1173 \mathrm{~cm}^{-1}$ represented the $\mathrm{C}-\mathrm{O}$ stretching vibration.

The comparison between the CW and CW/EG by using the infrared spectrum method indicated that the absorption peaks of the CW at 3446, 2918, 2849, 1736, 1463, 1173 and $719 \mathrm{~cm}^{-1}$ had the same appearance positions as to the CW/EG spectra; while the maximums of the both occurred at the middle infrared region $\left(4000-400 \mathrm{~cm}^{-1}\right)$, which indicated that there was no chemical interaction between CW and EG, while combination of the both was carried out by the physical absorption only.

The infrared spectrum of the CW/EG composite at pre- and post- cooling \& heating cycling were shown in Fig. 3(b). The absorption peaks of the CW/EG at 3446, 2918, 2849, 1736, 1463, 1173 
and $719 \mathrm{~cm}^{-1}$ before and after cycling were appeared at the same position. This indicated that the CW/EG remained excellent chemical stability throughout the cooling / heating cycling period.

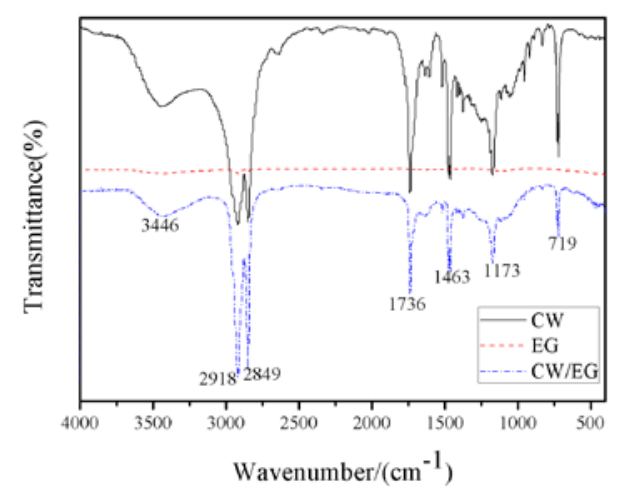

Fig. 3(a). Infrared spectrum of CW, EG and CW/EG.

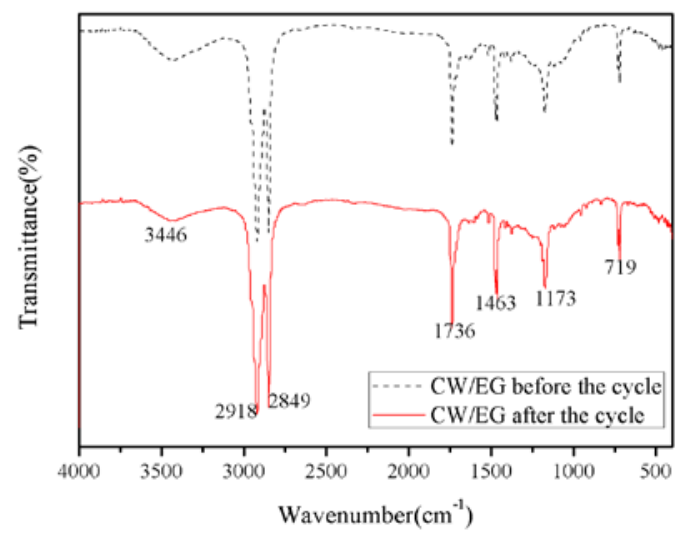

Fig. 3(b). Infrared spectrum of CW/EG before-and-after 1000 times of cycle.

\subsection{Thermal conductivity}

The thermal conductivity of the CW and CW/EG samples were measured using the thermal constant analyzer (Hot Disk, Sweden, model number 2500-OT). During this process, both the CW and CW/EG samples were pressurized to 20MPa by a mechanical molding press. Table 4 presents the measurement results for the test samples, which indicates that thermal conductivities of the CW and CW/EG were $0.3404 \mathrm{~W} / \mathrm{m} . \mathrm{K}$ and $5.92 \mathrm{~W} / \mathrm{m} . \mathrm{K}$, respectively. Compared to the CW alone, thermal conductivity of the CW/EG is increased by 16.4 times.

Table 4. Parameters of the test samples

\begin{tabular}{ccccccc}
\hline Samples & $\begin{array}{c}\text { Diameter } \\
\mathrm{mm}\end{array}$ & $\begin{array}{c}\text { Height } \\
\mathrm{mm}\end{array}$ & $\begin{array}{c}\text { Volume } \\
\mathrm{M}^{3}\end{array}$ & $\begin{array}{c}\text { Mass } \\
\mathrm{g}\end{array}$ & $\begin{array}{c}\text { Density } \\
\mathrm{kg} / \mathrm{m}^{3}\end{array}$ & $\begin{array}{c}\text { Thermal conductivity } \\
\mathrm{W} /(\mathrm{m} \cdot \mathrm{k})\end{array}$ \\
\hline CW & 30 & 10.75 & $7.59 \times 10^{-6}$ & 7.31 & 963 & 0.3404 \\
CW/EG & 30 & 9.93 & $7.02 \times 10^{-6}$ & 7.02 & 1000 & 5.92 \\
\hline
\end{tabular}




\subsection{Melting \& solidification cycling}

The melting \& solidification cycling performance of the CW and CW/EG was tested using a thermostat water bath, aiming at investigation of the impact of the EG additive to the time duration of the PCM melting and solidification. During the experiment, samples of the CW alone and CW/EG composite with the optimal mass ratio of 10 to 1 were tested using the cold/heat thermostat water bath (Julabo, Germany, model number ED-27), temperature data acquisition instrument (Agilent, model number 34980A) and thermocouples (model T, precision 0.25). This experiment was carried out with the operational procedure detailed below:

(1) Part I - Experimental set-up: This involved (a) weighing the $10 \mathrm{~g}$ of CW and CW/EG samples individually; (b) putting them into two equal-sized plastic tubes and then compressing them firmly; (c) inserting the thermocouples into the test tubes, in which the probes were positioned to the center of the samples; (d) connecting the thermocouples into the temperature data acquisition instrument; and (e) turning the cold/heat thermostat water bath on, and fixing the lower and upper temperature limits to $65{ }^{\circ} \mathrm{C}$ and $95{ }^{\circ} \mathrm{C}$, respectively.

(2) Part II - Melting experiment: This involved (a) putting the sample tubes into the thermostat water bath with the setting temperature of $65^{\circ} \mathrm{C}$, and keeping the sample tubes in the bath for the duration of 15 minutes after the thermocouple readings no longer rise; (b) putting the sample tubes into the thermostat water bath of $95^{\circ} \mathrm{C}$. The experiment was completed when the thermocouple readings were stabilized.

(3) Part III - Solidification experiment: This involved (a) putting the sample tubes into the thermostat water bath with the setting temperature of $95^{\circ} \mathrm{C}$, and keeping them for the duration of 15 minutes after the thermocouple readings no long rise; (b) putting them into the thermostat water bath with the setting temperature of $65^{\circ} \mathrm{C}$. The experiment was completed when the thermocouple readings were stabilized.

Based on the above measurements, impact of the thermal conductivity to the melting/solidification timings of the PCMs was investigated. The results indicated that higher thermal conductivity led 
to shorter melting/solidification timing. The temperature variation of the CW and CW/EG against timing is shown in Fig. 4. When the sample temperature grew from $65^{\circ} \mathrm{C}$ to $93^{\circ} \mathrm{C}$, the melting timings of the CW and CW/EG were 87 and 16 minutes respectively, indicating that the melting timing of the CW/EG was reduced by $81.7 \%$ compared to that of the CW alone. When the sample temperature fell from $93^{\circ} \mathrm{C}$ to $65^{\circ} \mathrm{C}$, the solidification timings of the $\mathrm{CW}$ and CW/EG were 58 minutes and 26 minutes respectively, indicating that the solidification timing of the CW/EG was reduced by $55.3 \%$ compared to that of the $\mathrm{CW}$ alone.

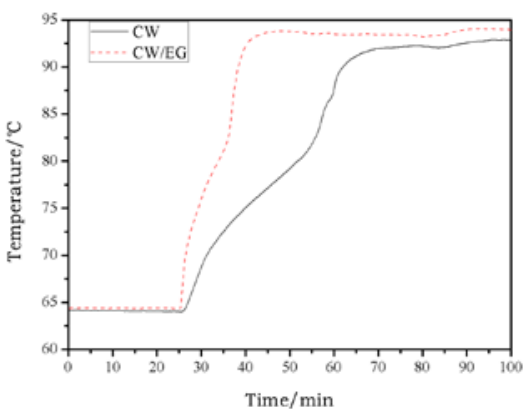

(a) melting curve

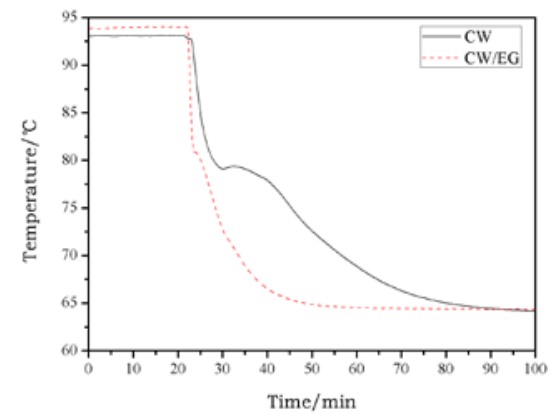

(b) solidification curve

Fig. 4 The temperature-time curve of samples in melting and solidification process.

Overall, the timings of the CW/EG melting and solidification were all less than that of the CW alone, indicating that increased thermal conductivity led to a faster melting and solidification.

\subsection{Accelerated cooling \& heating cycling}

The accelerated cooling \& heating cycling experiment was carried out by using the metal bath (BIOER ThermoQ, China, model number CHB-T2-E) and differential scanning calorimetry (TA company in United States, model number TAQ20), aiming at examination of the thermal stability of the PCMs. The experimental process including instrument information is shown schematically in Fig. 5. The whole experiment was carried out with the operational procedure detailed below:

(1) Part I - Experimental set-up: This involved (a) putting the CW/EG with the optimal mass ratio of 10:1 and CW samples respectively into the test tubes; (b) switching the metal bath on and keeping it for the duration of 60 seconds after the heat source temperature reached $95^{\circ} \mathrm{C}$; (c) cooling the sample down to the cold source temperature of $65^{\circ} \mathrm{C}$. 
(2) Part II - Cooling \& heating cycling: Repeating the above cycling for 1000 times, thus completing the accelerated cooling and heating cycling.

(3) Part III - Sample testing and characterization: By using the DSC, thermal and physical properties of the PCM composite samples before and after the cycling were measured, with the focus on the variation of the phase change temperature and latent heat. During the experiment, temperature of the DSC was set to $0.1^{\circ} \mathrm{C}$ while its enthalpy accuracy was set to $0.4 \%$; the $\mathrm{N}_{2}$ flow rate was set to $60 \mathrm{ml} / \mathrm{min}$, and its heating rate was fixed to $5^{\circ} \mathrm{C} /$ minute.

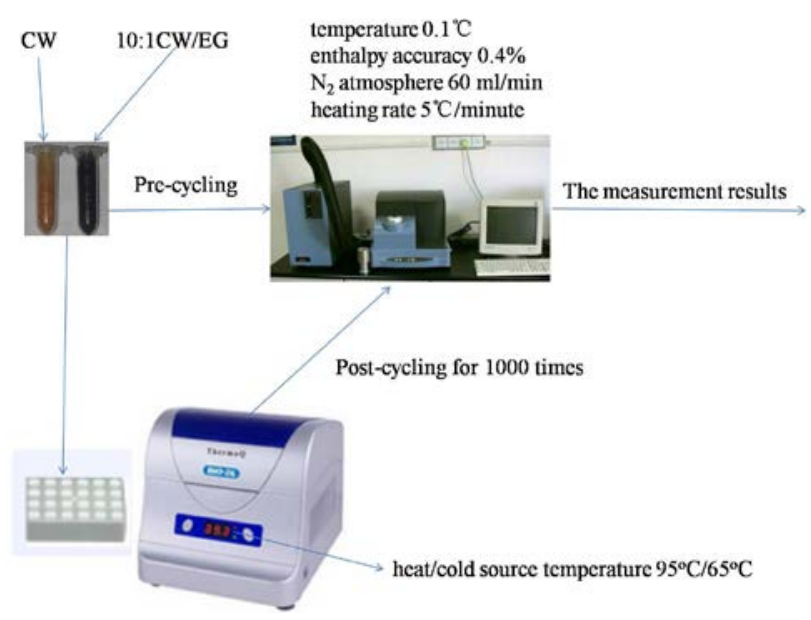

Fig. 5 The experimental process of accelerated cooling \& heating cycling

The measurement results for the CW and CW/EG are shown in Table 5 and Fig. 6. On this basis, the thermal stability of the PCM composite was analysed, detailed below:

In terms of the CW, the continuous cooling \& heating cycling operation led to the increase in endothermic/exothermic phase change temperatures by $0.34^{\circ} \mathrm{C}$ and $0.33^{\circ} \mathrm{C}$ respectively, which were $0.42 \%$ higher than the pre-cycling values. In terms of the CW/EG, this operation led to the increase in endothermic/exothermic phase change temperatures by $0.19^{\circ} \mathrm{C}$ and $0.22^{\circ} \mathrm{C}$ respectively, which were $0.23 \%$ and $0.27 \%$ higher than the pre-cycling values. At both the pre- and postcycling, the exothermic phase change temperatures of the CW and CW/EG were always less than the endothermic temperatures. As shown in Fig. 6, the peak exothermic temperatures of the both appeared to be at the left side of the peak endothermic temperatures. 
During the endothermic process, the pre-cycling latent heats of the CW and CW/EG were 169.5J/g and 150.9J/g respectively; while the post-cycling latent heats were $161.1 \mathrm{~J} / \mathrm{g}$ and $147.8 \mathrm{~J} / \mathrm{g}$ respectively, which were reduced by $4.96 \%$ and $2.05 \%$. During the exothermic process, the pre-cycling latent heats of the CW and CW/EG were 159.1J/g and 142.6J/g respectively; while the post-cycling latent heats were $151.5 \mathrm{~J} / \mathrm{g}$ and $137.7 \mathrm{~J} / \mathrm{g}$ respectively, which were reduced by $4.78 \%$ and $3.44 \%$.

Variation trends of the latent heat against temperature at both the pre- and post- cycling were found to be similar each other. The catch-up area of the post-cycling variation curve was slightly less than that of the pre-cycling one. The tiny variations in the latent heat and phase change temperature of the CW and CW/EG indicated that both the PCMs presented relatively stable thermal performance throughout the cooling \& heating cycling period. Compared to the CW only, the CW/EG composite had slightly better thermal stability.

Table 5. Variation of phase change temperature and latent heat before and after the accelerated cooling/thermal cycle.

\begin{tabular}{|c|c|c|c|c|c|c|c|c|}
\hline \multirow{4}{*}{ Materials } & \multicolumn{4}{|c|}{ Before cooling/thermal cycle } & \multicolumn{4}{|c|}{ After cooling/thermal cycle } \\
\hline & \multicolumn{2}{|c|}{ Endothermic process } & \multicolumn{2}{|c|}{ Exothermic process } & \multicolumn{2}{|c|}{ Endothermic process } & \multicolumn{2}{|c|}{ Exothermic process } \\
\hline & $\begin{array}{c}\text { Phase } \\
\text { change } \\
\text { temperature }\end{array}$ & $\begin{array}{c}\text { Latent } \\
\text { heat }\end{array}$ & $\begin{array}{c}\text { Phase } \\
\text { change } \\
\text { temperature }\end{array}$ & $\begin{array}{c}\text { Latent } \\
\text { heat }\end{array}$ & $\begin{array}{c}\text { Phase } \\
\text { change } \\
\text { temperature }\end{array}$ & $\begin{array}{c}\text { Latent } \\
\text { heat }\end{array}$ & $\begin{array}{c}\text { Phase } \\
\text { change } \\
\text { temperature }\end{array}$ & $\begin{array}{c}\text { Latent } \\
\text { heat }\end{array}$ \\
\hline & ${ }^{\circ} \mathrm{C}$ & $\mathrm{J} / \mathrm{g}$ & ${ }^{\circ} \mathrm{C}$ & $\mathrm{J} / \mathrm{g}$ & ${ }^{\circ} \mathrm{C}$ & $\mathrm{J} / \mathrm{g}$ & ${ }^{\circ} \mathrm{C}$ & $\mathrm{J} / \mathrm{g}$ \\
\hline CW & 81.82 & 169.5 & 78.82 & 159.1 & 82.16 & 161.1 & 79.15 & 151.5 \\
\hline $\mathrm{CW} / \mathrm{EG}$ & 81.98 & 150.9 & 80.43 & 142.6 & 82.17 & 147.8 & 80.65 & 137.7 \\
\hline
\end{tabular}

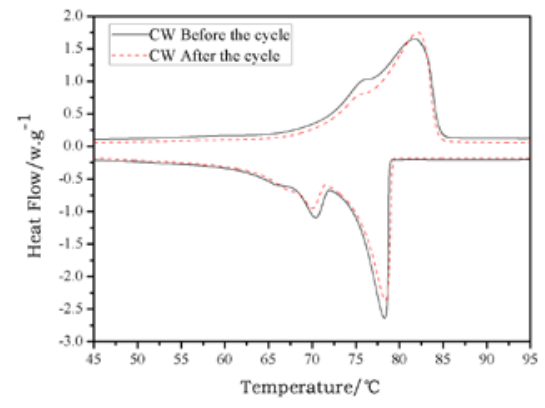

(a) $\mathrm{CW}$

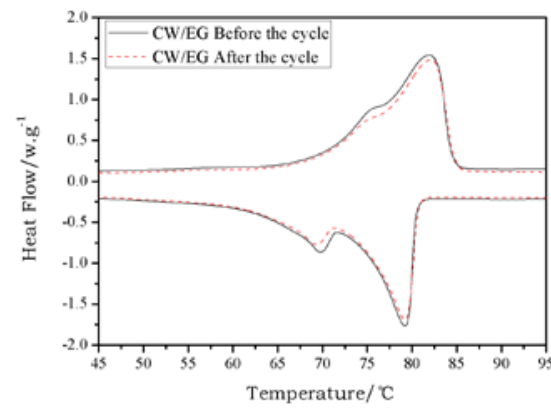

(b) CW/EG

Fig. 6. DSC curve before and after the accelerated cooling/thermal cycling

\section{Conclusion}

Throughout the research, a dedicated CW/EG composite was selected as the PCM candidate that is 
appropriate to the cold storage condensation heat recovery. The Carnauba Wax (CW) has a phase change temperature of around $80^{\circ} \mathrm{C}$ which meets the temperature requirement for heat recovery; while the Expanded Graphite (EG) provides enhanced thermal conductivity for the composite, thus overcoming the disadvantage of the low heat transport capacity of the existing CW materials. The optimal CW/EG mass ratio was 10:1, which could prevent extraction of the CW during the cooling \& heating cycling operation and meanwhile deliver the highest possible latent heat. The phase change temperatures of the CW/EG composite during the melting and solidification processes were $81.98^{\circ} \mathrm{C}$ and $80.42^{\circ} \mathrm{C}$ respectively; while the corresponding latent heats were 150.9 $\mathrm{J} / \mathrm{g}$ and $142.6 \mathrm{~J} / \mathrm{g}$.

Compared to the CW alone, the CW/EG composite could achieve 17.4 time higher thermal conductivity. As a result, the melting and solidification timings of the CW/EG were reduced by $81.7 \%$ and $55.3 \%$, respectively.

After the accelerated cooling and heating cycling operation, there were very tiny variations in phase change temperature and latent heat of both the CW and CW/EG composite, indicating that the both had excellent thermal stability.

In terms of the infrared spectrum of the CW, EG and CW/EG, the absorption peaks of the CW and CW/EG appeared at the almost same position, indicating that the EG and CW could be well combined by the physical absorption method. Furthermore, the absorption peaks of the CW/EG remained the same throughout the cooling \& heating cycling period, indicating that the CW/EG composite had excellent chemical stability.

This study delivered the important data and method appropriate to PCM selection and analysis for the cold storage condensation heat recovery, and thus contributes to achieving the energy saving and carbon reduction targets in the refrigeration sector, both in China and globally.

\section{Acknowledgements:}

This research is supported by the 2014 provincial Special Funds of Building Energy Saving of 
Sichuan Province and Youth Science and Technology Innovation Team of Sichuan Province of Building Environment and Energy Efficiency (Grant No: 2015TD0015).

\section{References:}

[1] Xie K, Xie B, Chen T, et al. Analysis on the reclamation of low quality exhausting thermal energy from refrigerated warehouse. Energy Conservation Technology 2007; 25:399-402.(in chinese)

[2] Zheng D, Liu W, Han X, et al. The condensing heat recovery of existing cold storage. Low Temperature Architecture Technology 2011;33:113-5.(in chinese)

[3] Li M, Li Z, Jiang X, et al. Design and performance analysis of the heat pump-based condensing heat of cold storage recovery drying equipment. In:Proceedings 2011 International Conference on Computer Distributed Control and Intelligent Environmental Monitoring(CDCIEM2011), 2011, 158-61.

[4] Zalba B, Marin J, Cabeza L, et al. Review on thermal energy storage with phase change: materials, heat transfer analysis and applications. Appl Therm Eng 2003; 23:251-83.

[5] Yuan Y, Zhang N, Tao W, et al. Fatty acids as phase change materials: a review. Renew Sustain Energy Rev 2014; 29:482-98.

[6] Wang L, Meng D. Fatty acid eutectic/polymethyl methacrylate composite as form-stable phase change material for thermal energy storage. Applied Energy 2010; 87:2660-5.

[7] Cemil A, Yusuf T, Derya K. Preparation and characterization of a series of thiourea derivatives as phase change materials for thermal energy storage. Turkish Journal of Chemistry 2011;35:769-77.

[8] Zhang X, Yu S, Yu M, et al. Experimental research on condensing heat recovery using phase change material. Applied Thermal Engineering 2011; 31:3736-40.

[9] Al-Abidi A, Mat S, Sopian K, et al. Review of thermal energy storage for air conditioning systems. Renewable and Sustainable Energy Reviews 2012; 16:5802-19.

[10] Moreno P, Solé C, Castell A, et al. The use of phase change materials in domestic heat pump and air-conditioning systems for short term storage: a review. Renewable and Sustainable Energy Reviews 2014;39:1-13.

[11] Fang G, Li H, Chen Z, et al. Preparation and characterization of stearic acid/expanded 
graphite composites as thermal energy storage materials. Energy 2010; 35:4622-6.

[12] Yuan Y, Yuan Y, Zhang N, et al. Preparation and thermal characterization of capric-myristic-palmitic acid/expanded graphite composite as phase change material for energy storage. Materials Letters 2014;125:154-7.

[13] Zhang N, Yuan Y, Du Y, et al. Preparation and properties of palmitic-stearic acid eutectic mixture/expanded graphite composite as phase change material for energy storage. Energy 2014;78:950-6.

[14] Yang X, Yuan Y, Zhang N, et al. Preparation and properties of myristic-palmitic-stearic acid/expanded graphite composites as phase change materials for energy storage. Solar Energy 2014;99:259-66.

[15] Zhang Y, Hu H, Kong X, et al. Phase-change energy storage---(theory and application). Hefei: University of Science and Technology of China Press, 1996:30-31.(in chinese)

[16] Tumirah K, Hussein MZ, Zulkarnain Z, et al. Nano-encapsulated organic phase change material based on copolymer nanocomposites for thermal energy storage. Energy 2014;66:881-990.

[17] Sar1 A, Karaipekli A. Thermal conductivity and latent heat thermal energy storage characteristics of paraffin/expanded graphite composite as phase change material. Appl Therm Eng 2007;27:1271-7.

[18] Karaipekli A, Sarı A, Kaygusuz K. Thermal conductivity improvement of stearic acid using expanded graphite and carbon fiber for energy storage applications. Renew Energy 2007;32:2201-10.

[19] Sarı A, Karaipekli A. Preparation, thermal properties and thermal reliability of palmitic acid/expanded graphite composite as form-stable PCM for thermal energy storage. Sol Energ Mat Sol Cells 2009;93:571-6.

[20] Kousksou T, Jamil A, Rhafiki T.EI, et al. Paraffin wax mixtures as phase change materials. Solar Energy Materials \& Solar Cells 2010;94:2158-65.

[21] Zhong Y, Guo Q, Li S, et al. Heat transfer enhancement of paraffin wax using graphite foam for thermal energy storage. Solar Energy Materials \& Solar Cells 2010;94:1011-4.

[22] Zhang Z, Zhang N, Peng J, et al. Preparation and thermal energy storage properties of paraffin/expanded graphite composite phase change material. Applied Energy 2012; 91:426-31. 
[23] Zhang N, Yuan Y, Wang X, et al. Preparation and characterization of lauric-myristic-palmitic acid ternary eutectic mixtures/expanded graphite composite phase change material for thermal energy storage. Chemical Engineering Journal 2013; 231:214-9.

[24] Li T, Lee JH, Wang R, et al. Enhancement of heat transfer for thermal energy storage application using stearic acid nanocomposite with multi-walled carbon nanotubes. Energy 2013; 55:752-61.

[25] Zhang N, Yuan Y, Yuan Y. Lauric-palmitic-stearic acid/expanded perlite composite as form-stable phase change material: Preparation and thermal properties. Energy and Buildings 2014; 82:505-11.

[26] Zhang N, Yuan Y, Yuan Y, et al. Effect of carbon nanotubes on the thermal behavior of palmitic-stearic acid eutectic mixtures as phase change materials for energy storage. Solar Energy 2014; 110:64-70.

[27] Liu C, Yuan Y, Zhang N, et al. A novel PCM of lauric-myristic-stearic acid/expanded graphite composite for thermal energy storage. Materials Letters 2014; 120:43-46.

[28] Seeniraj R, Velraj R, Narasimhan N. Thermal analysis of a finned-tube LHTS module for a solar dynamic power system. Heat and Mass Transfer 2002; 38:409-17.

\section{Highlights:}

1. A new method using PCM to recover condensation heat in the cold storages was proposed.

2. CW with phase change temperature of around $80^{\circ} \mathrm{C}$ was selected as the potential PCM.

3. The optimal mass ratio between the CW and EG was 10:1.

4. The thermal and physical performance of the CW/EG was investigated.

5. The thermal stability was demonstrated by 1000 cycles. 